\title{
Antinociceptive activity of Thyme (Thymus vulgaris $L$. ) and interactions with neurotropics and analgesics
}

\author{
Aleksandar Lazar Raškovići ${ }^{\text {, Maja Petar Kvrgić }}{ }^{\text {, Ana Drago Tomas }}{ }^{\circledR 1}$, \\ Nebojša Petar Stilinovićc ${ }^{1}$ Velibor Spasoje Čabarkapa ${ }^{3}$, \\ Anastazija Đurica Stojšić-Milosavljević ${ }^{4}$, Milica Nada Paut Kusturica1, \\ Dušica Branko Rakić 5
}

\author{
${ }^{1}$ University of Novi Sad, Faculty of Medicine, Department of Pharmacology, Toxicology and \\ Clinical Pharmacology, Hajduk Veljkova 3, Novi Sad, Serbia, " "Pharmacy" Novi Sad, Rumenačka \\ 1, Novi Sad, Serbia, ${ }^{3}$ Institute of Laboratory Diagnostics, Clinical Centre of Vojvodina, Hajduk \\ Veljkova 1, Novi Sad, Serbia, ${ }^{4}$ University of Novi Sad, Faculty of Medicine, Hajduk Veljkova 3, Novi \\ Sad, Serbia, ${ }^{5}$ Institute for Cardiovascular Diseases of Vojvodina, Vojvodina, Novi Sad, Serbia
}

\begin{abstract}
The plant world represents an important source of potential therapeutic agents, but concomitant administration of herbal and conventional medications may result in interactions with subsequent beneficial or adverse effects. This study was designed to examine the analgesic effect of thyme tincture and thyme syrup, two commonly used thyme formulations, and their interactions with codeine, paracetamol, pentobarbital and diazepam in mice. The identification and quantification of thymol and carvacrol were carried out by GC/MS and GC/FID. The analgesic activity was studied using a hot plate method. Effects of thyme syrup on diazepam-induced motor coordination impairment in rotarod test and on pentobarbital-induced sleeping time were also determined. Thymol $(175.3 \mu \mathrm{g} /$ $\mathrm{mL}$ and $9.73 \mu \mathrm{g} / \mathrm{mL})$ and carvacrol $(10.54 \mu \mathrm{g} / \mathrm{mL}$ and $0.55 \mu \mathrm{g} / \mathrm{mL})$ concentrations were measured in tincture and syrup, respectively. Thyme syrup and tincture exhibited effective analgesic activity in the hot plate pain model. Pretreatment with thyme formulations reduced analgesic activity of codeine, and potentiated the analgesic activity of paracetamol. Co-administration of thyme formulations has led to potentiation of diazepam and pentobarbital depressive central nervous system effects. Thyme formulations interacted with tested conventional drugs, probably through interference with their metabolic pathways and succeeding altered concentrations and pharmacological effects.
\end{abstract}

Keywords: Thymus vulgaris. Hot plate. Analgesic. Interactions. Pentobarbital. Diazepam.

\section{INTRODUCTION}

The lack of a potent analgesic drugs with less severe side effects than the ones available prompted many investigators to turn to the plant-derived extracts and phytochemicals in search for the safe and effective analgesics (Rašković et al., 2015a). Thyme (Thymus vulgaris L., Lamiaceae), a perennial herb native in

*Correspondence: A. D. Tomas. Department of Pharmacology, Toxicology and Clinical Pharmacology. Faculty of Medicine Novi Sad. University of Novi Sad. Hajduk Veljkova 3, 21000 Novi Sad, Serbia. Phone: $\quad+38121$ 522 172; Fax: +381 216615 771. E-mail: ana.tomas@mf.uns.ac.rs; aanaa tomas@yahoo.com central and southern Europe, Africa and Asia, beyond its common use as a food seasoning, has been used in traditional medicine for a myriad of indications, including laryngitis, tonsillitis, pertussis, bronchitis, dyspepsia, chronic gastritis, asthma and diarrhea (EMA, 2013; Ekor, 2013; Wachtel-Galor, Benzie, 2011). Pharmacological effects of thyme are attributed to two phenolic compounds, natural terpenoid thymol and its phenol isomer carvacrol (Golparvar, Hadipanah, 2014), which exhibit anxiolytic, anticonvulsive, antiinflammatory, antioxidant and antimicrobial properties (Bakkali et al., 2008; Chizzola et al., 2008; Guimarães et al., 2010; Melo et al., 2012; Melo et al., 2010; Vogt- 
Eisele et al., 2007). Studies examining thyme isolated constituents also documented an analgesic potential, but information is scant on the pain-relieving properties of commercially available Thymus Vulgaris formulations. This deserves attention, as different extracts of other species of genus Thymus, Thymus broussonetii and Thymus kotschyanus, exerted an antinociceptive activity in various experimental pain models (Elhabazi et al., 2006, Nikoui et al., 2016).

However, a growing body of scientific literature reported that thyme and its constituents may affect activity of liver enzymes, which is known to be the most common mean of interaction between herbal and conventional drugs (Meng, Liu, 2014). Foster BC et al., (2003) reported that an aqueous thyme extract significantly inhibited in vitro several isoforms of CYP 450, Sasaki et al., (2005) stated that a diet containing thyme (up to $2 \%$ ) as well as oral thymol and carvacrol $(200 \mathrm{mg} / \mathrm{kg})$ given once a day over 7 days induced the activity of phase I and phase II enzymes in the mouse liver up to $90 \%$ (Foster et al., 2003; Sasaki et al., 2005). Recent in vitro study which examined the effects of carvacrol on major UGT isoforms demonstrated that carvacrol significantly inhibited the activity of UGT1A9, with a negligible influence on other UGT isoforms (Dong et al., 2012). Another substance, 8-methoxycirsilineol, isolated from Thymus saturoides, demonstrated an inhibitory effect on CYP1A2 and CYP3A4 enzymes in-vitro. This compound has also been isolated from Thymus vulgaris (EMA, 2013; Brahmi et al., 2011).

It is well known that herbal drugs are generally perceived as being completely safe (Ekor 2013), and patients may therefore use them without hesitation together with different conventional drugs. However, potentially serious interactions may arise with concomitant administration of thyme preparations and different analgesic and neurotropic drugs, due to potent pharmacological properties of these phytochemicals (Fasinu et al., 2012). Taking all of the above into account, this study was designed to investigate and evaluate the antinociceptive effects of two commonly used pharmaceutical formulations containing thyme (Thymus vulgaris L.), tincture and syrup, and determine their interactions with codeine, paracetamol, as standard analgesic drugs, and pentobarbital and diazepam, as potent central nervous system depressors, in mice.

\section{MATERIAL AND METHODS}

\section{Chemicals and tested thyme formulations}

Thyme pharmaceutical formulations used in this study - tincture and syrup, were purchased from the Institute for Studies on Medicinal Plants 'Dr Josif Pančić' (Belgrade, Serbia) in 2012. A voucher specimen (Thymus vulgaris L. 1753 subsp. vulgaris No 2-1516, det.: Goran Anačkov) was verified and deposited in the Herbarium of the Department of Biology and Ecology, Faculty of Sciences, University of Novi Sad. The tincture was made from the aerial parts of the plant, Thymi herba, using ethanol $70 \%$ as extraction solvent in a 1:5 ratio, the plant material was macerated at room temperature for 24 hours with frequent agitation. Thyme syrup was made of thyme tincture $(15 \% \mathrm{w} / \mathrm{w})$, potassium bromide, simple syrup, methyl and propyl $p$-hydroxybenzoate as preservers, and water. Chemicals used in the experiments were purchased from Sigma Chemical Co. (St. Louis, MO, USA).

\section{Qualitative and quantitative analysis of thyme tincture}

The identification and quantification of thymol and carvacrol, as main chemical constituents of thyme tincture and syrup, were carried out by gas chromatography coupled with mass spectrometric detection (GC/MS) and flame ionization detection (GC/FID). GC/MS analysis was performed using an Agilent 7890A GC system equipped with 5975C VL MSD (Agilent Technologies, CA, USA). The capillary column used in this study was DB-5MS $(30 \mathrm{~m} \times 0.25$ $\mathrm{mm}$, film thickness of $0.25 \mu \mathrm{m}$; J\&W Scientific, CA, USA). The temperature program was set as follows: initial temperature $50{ }^{\circ} \mathrm{C}$ held for $1 \mathrm{~min}, 5^{\circ} \mathrm{C}$ per min to $100{ }^{\circ} \mathrm{C}, 9^{\circ} \mathrm{C}$ per min to $200^{\circ} \mathrm{C}$ held for $7.89 \mathrm{~min}$, and the total run time was $30 \mathrm{~min}$. The flow rate of helium as a carrier gas was $0.811851 \mathrm{~mL} / \mathrm{min}$. The MS system was operated in electron ionization (EI) mode with selected ion monitoring (SIM). The ion source temperature and quadrupole temperature were set at $230{ }^{\circ} \mathrm{C}$ and $150{ }^{\circ} \mathrm{C}$, respectively. Identification of thymol and carvacrol was performed by comparison of their retention times and mass spectra with those of authentic standards and with spectra in the NIST08.L, Flavor2.L and Wiley7n.1 libraries. GC/FID analysis was carried out using a Hewlett Packard 6890 chromatograph equipped with 
flame ionization detector, auto sampler and a split/ splitless injection system. The column DB-5MS $(60 \mathrm{~m}$ $\times 0.32 \mathrm{~mm}$, film thickness of $0.25 \mu \mathrm{m}$; J\&W Scientific, CA, USA) and helium as a carrier gas with flow rate of $1.9 \mathrm{~mL} / \mathrm{min}$ were used in this analysis. The injector and detector temperatures were set at $250{ }^{\circ} \mathrm{C}$ and $300{ }^{\circ} \mathrm{C}$, respectively, and the column temperature program was set as follows: initial temperature $60^{\circ} \mathrm{C}$ held for $1 \mathrm{~min}$, $10{ }^{\circ} \mathrm{C}$ per min to $265^{\circ} \mathrm{C}$ held for $8.5 \mathrm{~min}$, with the total run time of $30 \mathrm{~min}$. The concentrations of thymol and carvacrol were determined using the calibration curves prepared with standards of thymol and carvacrol, and cumene as internal standard.

\section{Animal experiments}

The study was conducted on adult Swiss albino mice of both sexes, weighing 25-30 g, obtained from the Veterinary Institute Novi Sad, Serbia. The animals were maintained under controlled room temperature $\left(23 \pm 1^{\circ} \mathrm{C}\right)$, light and dark $(12: 12 \mathrm{~h})$ conditions cycle with free access to tap water and standard pellet diet. Animal experiments were performed according to the European
Community guidelines (EEC Directive of 1986; 86/609/ EEC). Before conducting the experiment, ethical clearance was obtained from the Ethics Committee of the University of Novi Sad (Approval No. 01-53/7-1).

\section{Hot plate test}

To determine the effect of tested substances on hotplate induced nociceptive stimulus in mice, the animals were randomly divided into 9 experimental groups, each containing 6 individuals, and were treated as listed in the Table I. Substances were administered with oral gavage, through feeding tube, or as intraperitoneal injection. The doses of thyme tincture and syrup used in the experiment were adapted for the experimentation on mice using FDA guidance (FDA, 2005) according to the recommended human daily dose for a male with standard weight of $70 \mathrm{~kg}$ (ESCOP, 2003). Experiments were performed in a quite laboratory with an ambient temperature of $22 \pm 1{ }^{\circ} \mathrm{C}$. The thermal noxious stimulus was induced in mice by placing them in a hot-plate maintained at $52 \pm 1{ }^{\circ} \mathrm{C}$. Before the experiments, the basal reaction time response of all animals was measured.

TABLE I - Treatment protocols for control and treatment groups in the hot-plate test

\begin{tabular}{|c|c|c|}
\hline ConS & saline solution (10 mL/kg p.o.) & saline solution (10 mL/kg i.p.) \\
\hline Cod & saline solution (10 mL/kg p.o.) & codeine (30 mg/kg i.p.) \\
\hline Tin & thyme tincture $(0.4 \mathrm{~mL} / \mathrm{kg}$ p.o. $)$ & saline solution (10 mL/kg i.p.) \\
\hline Syr & thyme syrup (12.08 mL/kg p.o.) & saline solution (10 mL/kg i.p.) \\
\hline CodTin & thyme tincture (0.4 mL/kg p.o.) & codeine (30 mg/kg i.p.) \\
\hline CodSyr & thyme syrup (12.08 mL/kg p.o.) & codeine (30 mg/kg i.p.) \\
\hline ParSyr & thyme syrup (12.08 mL/kg p.o.) & paracetamol (60 mg/kg i.p.) \\
\hline
\end{tabular}

*30 minutes after the last dose of substance given in pretreatment; p.o. - per oral; i.p. - intraperitoneal 
Mice with baseline latency of more than 15 seconds were excluded from the study. The time between placement of the animal on the plate and shaking or licking of the paws or jumping, was measured and defined as the reaction time. A $45 \mathrm{sec}$ cut off was used to prevent tissue damage. The animals were subjected to the same test procedure at $0,+5,+10,+15,+20,+30,+40,+50$ and +60 minutes after the administration of test and control substances. The analgesic effect (AE) determined in seconds was expressed as the percentage increase in reaction time, calculated using the formula: $\mathrm{AE}(\%)=$ $[(\mathrm{Rt}-\mathrm{R} 0) / \mathrm{R} 0] \times 100$, where $\mathrm{Rt}=$ reaction time at time $\mathrm{t}$, and $\mathrm{R} 0=$ reaction time at time zero $(0 \mathrm{~h})$ (Vogel 2008).

\section{Induced sleeping time test}

To test the effects of thyme formulations on pentobarbital induced sleep, the animals were treated with thyme tincture $(0.4 \mathrm{~mL} / \mathrm{kg}$ p.o.) or thyme syrup (12.08 $\mathrm{mL} / \mathrm{kg}$ p.o.) for 7 days (control group received equivalent amount of saline), where the last dose on the 7th day was applied 45 minutes before i.p. administration of sodium pentobarbital $(40 \mathrm{mg} / \mathrm{kg})$. Following pentobarbital administration, animals were observed for onset of sleep. A mouse was considered to be asleep if it was placed on its back and displayed a loss of righting reflex for $5 \mathrm{~min}$ (Vogel, 2008). The latency of the loss of the righting reflex after drug administration (sleep induction time) and the time between the loss and the recovery of the righting reflex, duration (sleeping time) were determined for each animal.

\section{Rotarod (Forced Motor Activity) test}

To test the effect of thyme formulations on diazepam-induced motor coordination impairment, the animals were treated with thyme tincture $(0.4 \mathrm{~mL} /$ $\mathrm{kg}$ p.o.) or thyme syrup ( $12.08 \mathrm{~mL} / \mathrm{kg}$ p.o.) for 7 days (control group received equivalent amount of saline), where the last dose on the 7th day was applied 2 hours before i.p. administration of diazepam $(3 \mathrm{mg} / \mathrm{kg})$. Each animal was placed on a fixed speed rotating rod (20 $\mathrm{rpm}$ ) in a pretest session, and only those that were able to maintain balance for $5 \mathrm{~min}$, were included in the experiment. During the experiment, time in which the animals were able to maintain balance on the rotating rod was noted before and 10, 20, 30, 40, 50 and $60 \mathrm{~min}$ after diazepam administration.

\section{Statistical analysis}

The statistical analysis was carried out using ANOVA followed by Tukey's post hoc test using SPSS software, version (IBM SPSS, Chicago, IL, USA). In all cases, differences were considered significant if $\mathrm{p}<0.05$. All data are expressed as a mean \pm standard deviation (SD).

\section{RESULTS}

\section{Concentrations of thymol and carvacrol in thyme preparations}

Thymol and carvacrol, as the major phenolic active compounds of thyme, were identified and quantified in examined thyme formulations by GC/MS. Thymol $(175.3 \mu \mathrm{g} / \mathrm{mL}$ and $9.73 \mu \mathrm{g} / \mathrm{mL})$ and carvacrol $(10.54 \mu \mathrm{g} /$ $\mathrm{mL}$ and $0.55 \mu \mathrm{g} / \mathrm{mL}$ ) concentrations were measured in tincture and syrup, respectively. Monitor ions $(\mathrm{m} / \mathrm{z}$ values) used for quantification and confirmation GC/MS and chromatograms are available in previous publication (Rašković et al., 2015b). Retention times were 15.819 and 16.002 minutes for thymol and carvacrol, respectively.

\section{Hot plate test}

In the present study, pretreatment with thyme tincture and thyme syrup significantly delayed reaction time of the mice to the hot plate induced thermal stimulus compared to the saline treated group (Table II, selected post-administration time-points, full table available as supplement). The antinociception produced by the tested compounds lasted up to $60 \mathrm{~min}$ after their administration with the maximal effect between the 10th and 50th minute. Analgesic effect of thyme preparations was comparable to that of paracetamol, but significantly lower than codeine analgesic effect, especially between the 10th and 30th minute of the experiment. Influence of thyme formulation on analgesic effect of paracetamol and codeine, standard reference analgesic drugs, is shown in Figures 1 and 2. As seen in Figure 1, the analgesic effect of codeine was significantly lower after pretreatment with thyme tincture and syrup, compared to the mice treated with codeine alone. On the other hand, pretreatment with thyme tincture potentiated the analgesic effect of paracetamol in most of the postadministration time points (Figure 2). 
TABLE II - Effects of the 7 day pretreatment with Thymus Vulgaris tincture and syrup on the results of the hot plate test in mice. Data are presented as mean \pm S.E.M

\begin{tabular}{|c|c|c|c|c|c|}
\hline \multirow{2}{*}{ Group $(n=6)$} & \multicolumn{5}{|c|}{ Time (minutes) } \\
\hline & $\mathbf{0}$ & 10 & 15 & 30 & 60 \\
\hline ConS & $10.91 \pm 2.61$ & $9.87 \pm 2.17$ & $12.47 \pm 3.27$ & $10.91 \pm 2.87$ & $11.88 \pm 2.70$ \\
\hline Tin & $13.29 \pm 2.21$ & $19.67 \pm 4.79^{*}$ & $20.41 \pm 4.66^{*}$ & $16.14 \pm 4.11^{*}$ & $18.23 \pm 7.04$ \\
\hline Syr & $11.48 \pm 1.51$ & $13.90 \pm 3.31^{* * *}$ & $17.06 \pm 1.52$ & $16.93 \pm 5.26^{* * *}$ & $18.72 \pm 5.47$ \\
\hline Cod & $11.17 \pm 1.12^{*}$ & $23.54 \pm 4.59^{*}$ & $25.16 \pm 2.99^{*}$ & $25.83 \pm 5.73^{*}$ & $19.87 \pm 5.16$ \\
\hline Par & $10.07 \pm 1.93$ & $13.02 \pm 3.36$ & $15.85 \pm 3.82$ & $14.77 \pm 4.76$ & $15.42 \pm 4.99$ \\
\hline TinPar & $9.97 \pm 1.78$ & $13.77 \pm 1.92^{*}$ & $14.51 \pm 2.69$ & $12.66 \pm 3.25$ & $14.08 \pm 1.59$ \\
\hline SyrPar & $11.58 \pm 2.41$ & $16.27 \pm 4.7^{*}$ & $15.93 \pm 2.71$ & $14.26 \pm 3.57$ & $16.71 \pm 6.56$ \\
\hline TynCod & $12.5 \pm 2.59$ & $17.58 \pm 3.51$ & $18.37 \pm 6.13^{* *}$ & $15.99 \pm 5.40^{* * *}$ & $18.58 \pm 6.28$ \\
\hline SyrCod & $12.49 \pm 2.20$ & $19.28 \pm 6.07$ & $15.44 \pm 4.75^{* *}$ & $17.53 \pm 2.81^{* *}$ & $15.67 \pm 2.10$ \\
\hline
\end{tabular}

*- significantly different from ConS.

**- significantly different from Cod group.

***-significantly different from Par group

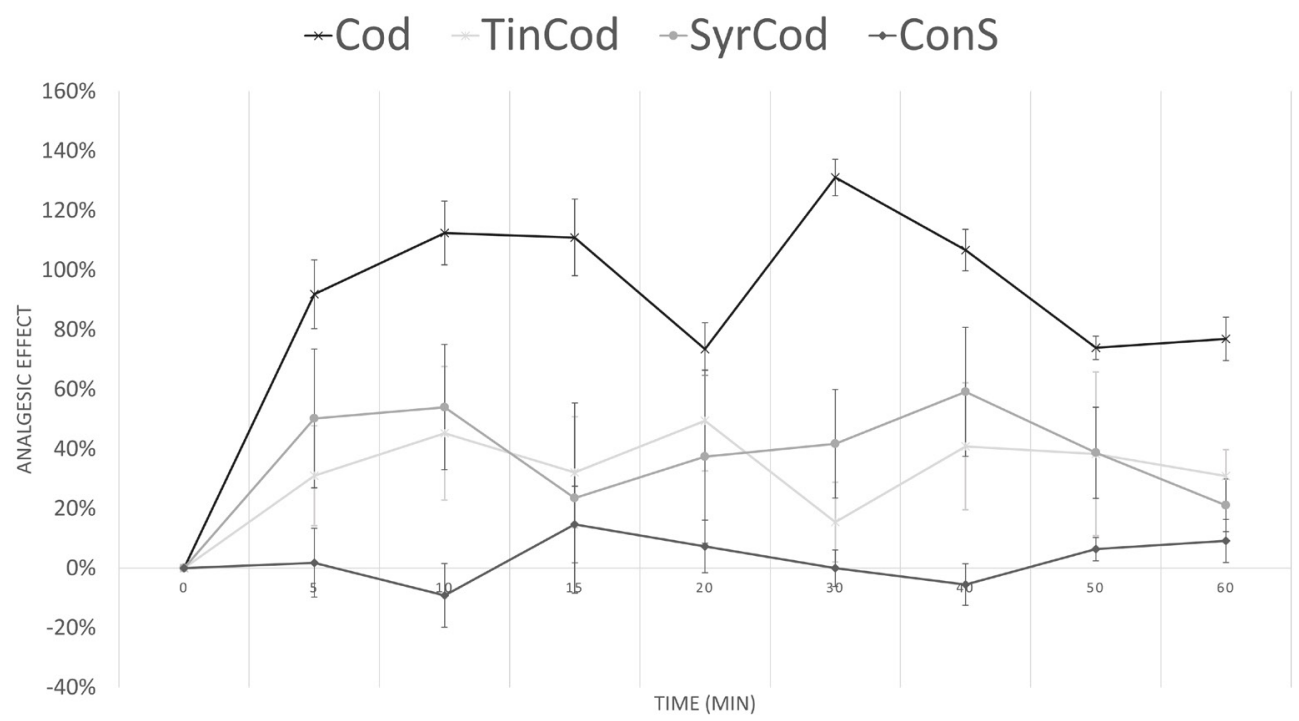

FIGURE 1 - Interactions between different Thyme formulations and codeine. Analgesic effect is expressed as a percentage of prolongation of measured reaction time compared to control reaction time (Abbreviations - ConS: control group, Tin: thyme tincture, Syr: thyme syrup, Cod: codeine, TinCod: thyme tincture and codeine, SyrCod: thyme syrup and codeine). 


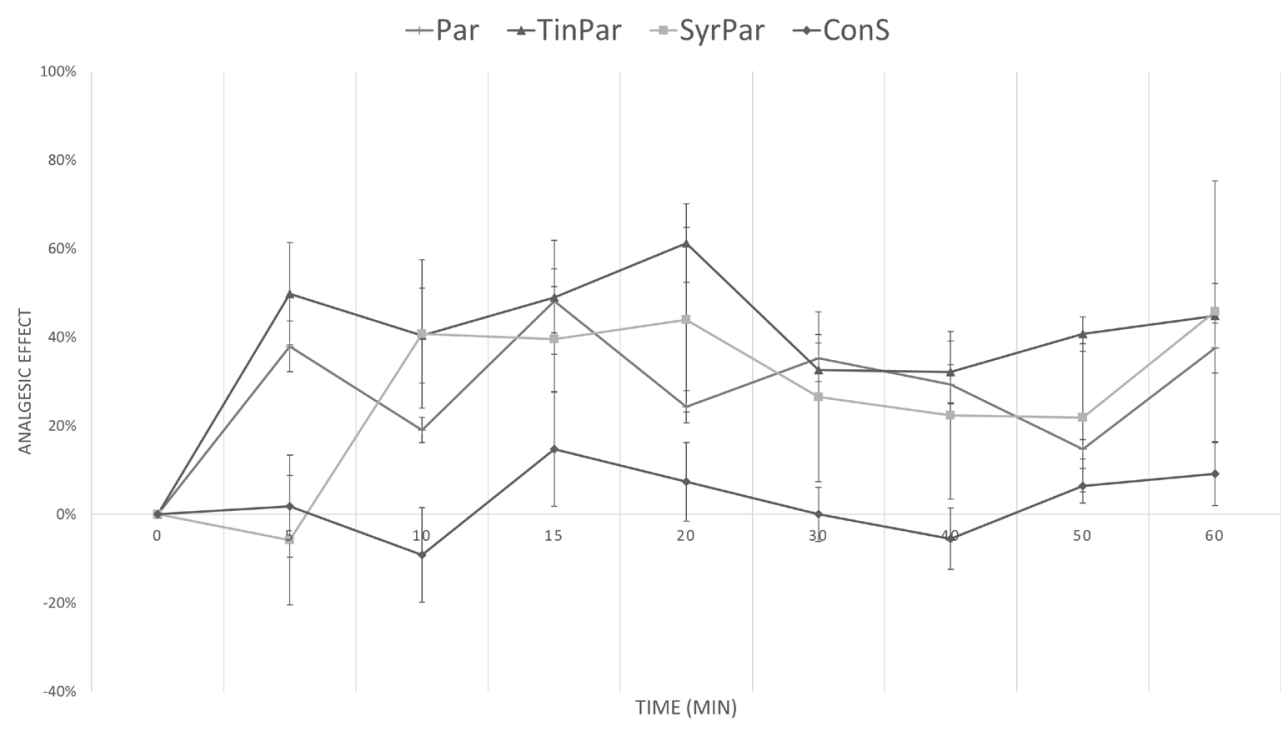

FIGURE 2 - Interactions between different Thyme formulations and paracetamol. Analgesic effect is expressed as a percentage of prolongation of measured reaction time compared to control reaction time (Abbreviations - ConS: control group, Tin: thyme tincture, Syr: thyme syrup, Par: paracetamol, TinPar: thyme tincture and paracetamol, SyrPar: thyme syrup and paracetamol).

\section{Forced motor activity test and pentobarbital induced sleeping time test}

The results of this study showed that thyme syrup potentiated diazepam-induced motor coordination impairment in mice (Table III). The difference was statistically significant after 20 minutes $(p=0.0049)$ and 30 minutes $(p=0.03)$ after the experiment started between the syrup and control group. Both examined thyme preparations had modulated pentobarbital's hypnotic effect, by shortening sleep induction and prolonging the duration of pentobarbital-induced sleeping time, but this difference was not statistically significant (Table IV).

TABLE III - The influence of Thymus vulgaris syrup and tincture on motor coordination impairment in mice caused by diazepam (values expressed as mean $\pm \mathrm{SD}$ ). The mean time of balance maintenance is shown in seconds

Time after diazepam administration (seconds)

\begin{tabular}{lccccccc} 
Group $(\mathbf{n}=\mathbf{6})$ & $\mathbf{0}$ & $\mathbf{1 0}$ & $\mathbf{2 0}$ & $\mathbf{3 0}$ & $\mathbf{4 0}$ & $\mathbf{5 0}$ & $\mathbf{6 0}$ \\
\cline { 2 - 7 } & 300 & $9.67 \pm 6.02$ & $105.33 \pm 34.89$ & $258.83 \pm 73.42$ & $300 \pm 0.00$ & $300 \pm 0.00$ & $300 \pm 0.00$ \\
ConDia & 300 & $32.80 \pm 18.62$ & $152.20 \pm 43.41$ & $201.20 \pm 15.51$ & $251 \pm 59.57$ & $243.6 \pm 66.11$ & $294.6 \pm 12.07$ \\
TinDia & 300 & $7.67 \pm 2.13$ & $45.83 \pm 25.96^{*}$ & $101.67 \pm 35.13^{*}$ & $170.83 \pm 23.13^{*}$ & $232.5 \pm 35.53$ & $290.83 \pm 22.45$ \\
SyrDia & & & &
\end{tabular}

$* \mathrm{p}<0.05$ compared with control group. 
TABLE IV - The effect of Thymus vulgaris syrup and tincture on pentobarbital-induced sleeping time (mean \pm SD)

\begin{tabular}{lcc}
\hline Group $(\mathbf{n}=\mathbf{6})$ & Sleep induction time $[\mathbf{m i n}]$ & Sleeping time [min] \\
\hline ConS & $4.83 \pm 1.56$ & $71 \pm 23.33$ \\
PentTin & $3.50 \pm 0.83$ & $76.17 \pm 21.22$ \\
PentSyr & $3.67 \pm 0.82$ & $83.33 \pm 26.21$ \\
\hline
\end{tabular}

\section{DISCUSSION}

In our study, the concentrations of the major components of the thyme, thymol and carvacrol, in studied formulations were determined and thymol was found to be predominant. The concentration of thymol in thyme syrup was approximately 17 times higher, while in thyme tincture it was 16 times higher, in comparison to carvacrol. A large amount of data concerning the chemical composition of thyme essential oil are presented in the scientific literature (Ebrahimi et al., 2008), as Thymus vulgaris is considered one of the best examples of chemotypic variation with seven different monoterpenes occurring in various ratios (Thompson et al., 2004). Chemical composition of the essential oil is dependent on a number of factors, such as the environment, geographical region and cultivation. Content of thymol and carvacrol in studied formulations implies that the plant used in our study belongs to thymol chemotype, which is in accordance with previous study that identified chemical profile of essential oil from Thymus vulgaris collected in Serbia as being of the same chemotype (Nikolić et al., 2014).

All investigated compounds exhibited analgesic effects in mice as demonstrated by the hot plate model of nociception. The 7-day treatment of both tested thyme formulations produced an elevation of the nociceptive threshold, measured by the increased latencies in the hot plate test. The analgesic activities of thyme tincture and syrup were comparable to that of paracetamol, and significantly lower than codeine at most of the postadministration time points. Analgesic activity of thyme essential oil and its components was confirmed before in different nociceptive experimental models. A dry Thymus vulgaris extract exhibited a dose dependent anti-nociceptive effect after intraperitoneal injection in formalin, tail flick and hot plate tests (Taherian et al., 2009). Other species of the genus Thymus also display analgesic effects. Different extracts of Thymus broussonetii and Thymus kotschyanus exerted an antinociceptive activity in various experimental pain models (Elhabazi et al., 2006; Nikoui et al., 2016). There is always a question which of the active components of whole extract of a medicinal plant is responsible for the observed pharmacological effect, and for Thymus vulgaris, thymol and carvacrol have been identified as the most important components. The mechanism of pain modulation by these phytochemicals is complex. Carvacrol modulates pain perception by affecting TRPA1 receptors, cation channels expressed in central nervous system related to hyperalgesia (Xu et al., 2006), inhibits formation of pro-inflammatory cytokine TNF- $\alpha$ (Guimarães et al., 2012), suppresses COX-2 expression (Hotta et al., 2010) and inhibits prostaglandin synthesis (Wagner et al., 1986). Its antioxidant activity can also contribute significantly to controlling pain (Guimarães et al., 2012). Thymol is known to activate TRPV3 receptors and may partially block voltage-gated sodium channels, which may be the molecular mechanism responsible for its pain-relieving properties (Haeseler et al., 2002; Xu et al., 2006). On the other hand, it has been shown that thymol directly activates TRPA1 (Lee et al., 2008), whose activation produces acute pain, neurogenic inflammation and vigorous hypersensitivity to thermal and mechanical stimuli (Bessac, Jordt, 2008).

Our study revealed that a pretreatment with thyme syrup, and especially thyme tincture, affected analgesic activity of paracetamol and codeine. At clinically relevant doses, thyme formulations decreased the analgesic effect of codeine and potentiated the analgesic effect of paracetamol. These findings go in favor of inhibitory effect of tested formulations on enzymes involved in codeine and paracetamol metabolism. Codeine is $\mathrm{O}$-demethylated to morphine, the most active metabolite 
with 200-fold greater affinity for the opioid receptors, by CYP2D6 (Smith 2009). Therefore, one possible explanation for reduced analgesic potency of codeine in mice pretreated with thyme syrup and tincture could be the inhibition of CYP2D6 and subsequent lower levels of active metabolites Raskovic et al., 2015a). Over 55\% of paracetamol is eliminated by glucuronidation, with uridine 5'-diphospho (UDP)-glucuronosyltransferase 1A9 identified as the predominant isoform responsible for its glucuronidation (Duan et al., 2001; Mutlib et al., 2006). A minor fraction (5-10\%) is metabolized through a pathway involving cytochrome $\mathrm{P} 450$ enzymes resulting in hepatotoxic metabolites (e.g. $N$-acetyl-pbenzoquinoneimine). As mentioned before, a recent in vitro study demonstrated that carvacrol significantly inhibited the activity of UGT1A9 (Dong et al., 2012), with a negligible influence on other UGT isoforms. Given the fact that UGT1A9 is involved in the metabolism of paracetamol, the inhibition of UGT1A9 by carvacrol may explain the increase in paracetamol analgesic activity, but this may also potentiate paracetamol hepatotoxicity (Kostrubsky et al., 2005). It is important to emphasize that behavioral components that can be measured in term of reaction times in the hot plate test, namely, licking and jumping, are considered to be supraspinally integrated responses (Le Bars et al., 2001). A number of neurotransmitter systems may be involved in the central analgesic activity of paracetamol (Pini et al., 1996), but recently, new findings into paracetamol mechanism of action identified TRPA1 receptor, an ion channel primarily expressed in vertebrate sensory neurons (Bessac, Jordt, 2008), as involved in paracetamol analgesic effect (Andersson et al., 2011). As both carvacrol and thymol affect the TRPA1, this may have also contributed to the modification of paracetamolinduced antinociception in the hot plate test.

The pretreatment with two thyme formulations potentiated the motor coordination impairment induced by diazepam in the rotarod test. It also decreased sleep latency and prolonged pentobarbital-induced sleeping time. This effect was more pronounced for the syrup compared to tincture. Both diazepam and pentobarbital demonstrate their effects through acute potentiation of inhibitory GABAergic tone, even though they possess different binding sites. It has been previously demonstrated that different phytochemical compounds in medicinal plants interact with GABAergic system to induce xenobiotics hypnotic effect (Chu et al., 2007; Nogueira, Vassilieff, 2000). Carvacrol has been identified as a potent $\mathrm{GABA} B$ agonist and thymol is a positive allosteric modulator of the GABA(A) receptor (García et al., 2006; Parker et al., 2014). In addition to possible synergistic interaction, potentiation of pharmacological properties of diazepam and pentobarbital may be the consequence of pharmacokinetic interference, through inhibition of their metabolic pathways. Pentobarbital undergoes aliphatic hydroxylation by cytochrome P450-dependent monooxygenases, probably CYP2B6 and CYP2D6 isoforms (Tsuji et al., 1996). Thus, this prolongation of pentobarbital-induced sleeping time in mice, indicates an inhibitory effect on enzymes involved in pentobarbital metabolism (Rašković et al., 2014). Diazepam is metabolized into active metabolites, which then undergo glucuronidation to form glucuronide conjugates, via CYP3A4-dependent hydroxylation and demethylation (Riss et al., 2008). Inhibition of CYP pathway in the liver would result in less active metabolites and suppressed diazepam action, but inhibition of CYP3A4 in the small intestine has been reported to increase the bioavailability of diazepam (Özdemir et al., 1998). Also, inhibition of glucuronidation of active diazepam metabolites by pretreatment with thyme formulations could have resulted in prolonged and enhanced diazepam action on GABA receptors.

\section{CONCLUSIONS}

Based on the results observed, it can be concluded that both thyme syrup and tincture, and their active ingredients thymol and carvacrol, exhibited effective analgesic activity in the hot plate pain model. Thyme formulations potentiated the analgesic activity of paracetamol and decreased the analgesic activity of codeine, significantly prolonged pentobarbital-induced sleep behavior and potentiated diazepam-induced motor coordination impairment in mice probably through interference with their metabolic pathways.

\section{CONFLICT OF INTEREST}

The authors declare that they have no competing interests.

\section{ACKNOWLEDGEMENT}

The authors would like to express their gratitude to Radomir Ratajac PhD, Veterinary Institute, Novi Sad, for providing experimental animals. 


\section{FUNDING}

This work was supported by the Provincial Secretariat for Science and Technological Development, Autonomous Province of Vojvodina (project No.114-4512178/2016-03), Ministry of Science and Technological Development, Republic of Serbia (project No. 41012) and MEDLEM, id 690876 - H2020-MSCA-RISE-2015.

\section{REFERENCES}

Andersson DA, Gentry C, Alenmyr L, Killander D, Lewis SE, Andersson A, et al. TRPA1 mediates spinal antinociception induced by acetaminophen and the cannabinoid $\Delta 9$ tetrahydrocannabiorcol. Nat Commun. 2011;2:551.

Bakkali F, Averbeck S, Averbeck D, Idaomar M. Biological effects of essential oils-a review. Food Chem Toxicol. 2008:46(2):446-475.

Bessac BF, Jordt S-E. Breathtaking TRP channels: TRPA1 and TRPV1 in airway chemosensation and reflex control. Physiology. 2008;23(6):360-370.

Brahmi Z, Niwa H, Yamasato M, Shigeto S, Kusakari Y, Sugaya K, et al. Effective Cytochrome P450 (CYP) inhibitor isolated from Thyme (Thymus saturoides) purchased from a Japanese market. Biosci Biotechnol Biochem. 2011;75(11):2237-2239.

Chizzola R, Michitsch H, Franz C. Antioxidative properties of Thymus vulgaris leaves: comparison of different extracts and essential oil chemotypes. J Agric Food Chem. 2008;56(16):6897-6904.

Chu Q-P, Wang L-E, Cui X-Y, Fu H-Z, Lin Z-B, Lin S-Q, et al. Extract of Ganoderma lucidum potentiates pentobarbitalinduced sleep via a GABAergic mechanism. Pharmacol Biochem Behav. 2007:86(4):693-698.

Dong RH, Fang ZZ, Zhu LL, Liang SC, Ge GB, Yang L, Liu ZY. Investigation of UDP-glucuronosyltransferases (UGTs) inhibitory properties of carvacrol. Phytother Res. 2012;26(1):86-90.

Duan SX, von Moltke LL, Greenblatt DJ, Patten CJ, Miners JO, Mackenzie PI. Interindividual variability in acetaminophen glucuronidation by human liver microsomes: identification of relevant acetaminophen UDP-glucuronosyltransferase isoforms. J Pharm Exp Ther. 2001;299(3):998-1006.

Ebrahimi SN, Hadian J, Mirjalili M, Sonboli A, Yousefzadi M. Essential oil composition and antibacterial activity of Thymus caramanicus at different phenological stages. Food Chem. 2008;110(4):927-931.
Ekor M. The growing use of herbal medicines: issues relating to adverse reactions and challenges in monitoring safety. Front Pharmacol. 2012;4:177.

Elhabazi K, Aboufatima R, Benharref A, Zyad A, Chait A, Dalal A. Study on the antinociceptive effects of Thymus broussonetii Boiss extracts in mice and rats. J Ethnopharmacol. 2006;107(3):406-411.

ESCOP. European Scientific Cooperative on Phytotherapy monographs. Thymi herba 2. pp 505-509. Stuttgart: Georg Thieme Verlag; 2003.

European Medicine Agency (EMA). Assessment report on Thymus vulgaris L., vulgaris zygis L., aetheroleum. 2013.

Fasinu PS, Bouic PJ, Rosenkranz B. An overview of the evidence and mechanisms of herb-drug interactions. Front Pharmacol. 2012;3:69.

Food and Drug Administration (FDA), Center for Drug Evaluation and Research, US Food and Drug Administration. Guidance for industry: estimating the maximum safe starting dose in initial clinical trials for therapeutics in adult healthy volunteers. Rockville MD: FDA; 2005.

Foster BC, Vandenhoek S, Hana J, Krantis A, Akhtar M, Bryan $\mathrm{M}$, et al. In vitro inhibition of human cytochrome P450-mediated metabolism of marker substrates by natural products. Phytomedicine. 2003;10(4):334-342.

García DA, Bujons J, Vale C, Suñol C. Allosteric positive interaction of thymol with the GABA A receptor in primary cultures of mouse cortical neurons. Neuropharmacol. 2006;50(1):25-35.

Golparvar A, Hadipanah A. Comparative effect of harvest time on essential oil and thymol content of (Thymus vulgaris L.) and (Thymus daenensis Celak) in Iran Province. E J Bio. 2014;10(3):85-92.

Guimarães AG, Oliveira GF, Melo MS, Cavalcanti SC, Antoniolli AR, Bonjardim LR, et al. Bioassay-guided evaluation of antioxidant and antinociceptive activities of carvacrol. Basic Clin Pharmacol Toxicol. 2010;107(6): 949-957.

Guimarães AG, Xavier MA, de Santana MT, Camargo EA, Santos CA, Brito FA, et al. Carvacrol attenuates mechanical hypernociception and inflammatory response. Naunyn Schmiedebergs Arch Pharmacol. 2012;385(3):253-263.

Haeseler G, Maue D, Grosskreutz J, Bufler J, Nentwig B, Piepenbrock S, et al. Voltage-dependent block of neuronal and skeletal muscle sodium channels by thymol and menthol. Eur J Anaesthesiol. 2002;19(08):571-579. 
Hotta M, Nakata R, Katsukawa M, Hori K, Takahashi S, Inoue H. Carvacrol, a component of thyme oil, activates PPAR $\alpha$ and $\gamma$ and suppresses COX-2 expression. J Lipid Res. 2010;51(1):132-139.

Kostrubsky SE, Sinclair JF, Strom SC, Wood S, Urda E, Stolz DB, et al. Phenobarbital and phenytoin increased acetaminophen hepatotoxicity due to inhibition of UDPglucuronosyltransferases in cultured human hepatocytes. Toxicol Sci 2005;87(1):146-155.

Le Bars D, Gozariu M, Cadden SW. Animal models of nociception. Pharmacol Rev. 2001;53(4):597-652.

Lee S, Buber M, Yang Q, Cerne R, Cortes R, Sprous D, Bryant $\mathrm{R}$. Thymol and related alkyl phenols activate the hTRPA1 channel. Br J Pharmacol. 2008;153(8):1739-1749.

Melo C, Helvira F, Rios ERV, Rocha NFM, Citó MCO, Fernandes ML, et al. Antinociceptive activity of carvacrol (5-isopropyl-2-methylphenol) in mice. J Pharm Pharmacol. 2012;64(12):1722-1729.

Melo FHC, Venâncio ET, De Sousa DP, De França Fonteles MM, De Vasconcelos SMM, Viana GSB, De Sousa FCF. Anxiolytic-like effect of Carvacrol (5-isopropyl2-methylphenol) in mice: involvement with GABAergic transmission. Fundam Clin Pharmacol. 2010;24(4):437-443.

Meng Q, Liu K. Pharmacokinetic interactions between herbal medicines and prescribed drugs: focus on drug metabolic enzymes and transporters. Curr Drug Metab. 2014;15(8): 791-807.

Mutlib AE, Goosen TC, Bauman JN, Williams JA, Kulkarni S, Kostrubsky S. Kinetics of acetaminophen glucuronidation by UDP-glucuronosyltransferases 1A1, 1A6, 1A9 and 2B15. Potential implications in acetaminophen-induced hepatotoxicity. Chem Res Toxicol. 2006;19(5):701-709.

Nikolić M, Glamočlija J, Ferreira IC, Calhelha RC, Fernandes $\hat{A}$, et al. Chemical composition, antimicrobial, antioxidant and antitumor activity of Thymus serpyllum L., Thymus algeriensis Boiss. and Reut and Thymus vulgaris L. essential oils. Ind Crops Prod. 2014;52:183-190.

Nikoui V, Ostadhadi S, Imran Khan M, Allahverdi A. Evaluation of the analgesic effect of Thymus kotschyanus hydroalcoholic extract in male mice by formalin and tail flick tests. J Basic Clin Physiol Pharmacol. 2016;4(1):1-6.

Nogueira E, Vassilieff V. Hypnotic, anticonvulsant and muscle relaxant effects of Rubus brasiliensis. Involvement of GABA A-system. J Ethnopharmacol. 2000;70(3):275-280.
Özdemir M, Aktan Y, Boydaĝ B, Cingi M, Musmul A. Interaction between grapefruit juice and diazepam in humans. Eur J Drug Metab Pharmacokinet. 1998;23(1):55-59.

Parker DA, Marino V, Ong J. Pharmacological actions of thymol and an analogue at GABAB autoreceptors. Clin Exp Pharmacol Physiol. 2014;41(9):623-627.

Pini LA, Sandrini M, Vitale G. The antinociceptive action of paracetamol is associated with changes in the serotonergic system in the rat brain. Eur J Pharmacol. 1996;308(1):31-40.

Rašković A, Cvejić J, Stilinović N, Goločorbin-Kon S, Vukmirović S, Mimica-Dukić N, Mikov M. Interaction between different extracts of Hypericum perforatum L. from Serbia and Pentobarbital, Diazepam and Paracetamol. Molecules. 2014;19(4):3869-3882.

Raskovic A, Milanovic I, Pavlovic N, Milijasevic B, Ubavic M, Mikov M. Analgesic effects of rosemary essential oil and its interactions with codeine and paracetamol in mice. Eur Rev Med Pharmacol Sci. 2015;9(1):165-172.

Rašković A, Pavlović N, Kvrgić M, Sudji J, Mitić G, Čapo I, Mikov M. Effects of pharmaceutical formulations containing thyme on carbon tetrachloride-induced liver injury in rats. BMC Complement Altern Med. 2015;15:442.

Riss J, Cloyd J, Gates J, Collins S. Benzodiazepines in epilepsy: pharmacology and pharmacokinetics. Acta Neurol Scand. 2008;118(2):69-86.

Sasaki K, Wada K, Tanaka Y, Yoshimura T, Matuoka K, Anno T. Thyme (Thymus vulgaris L.) leaves and its constituents increase the activities of xenobiotic-metabolizing enzymes in mouse liver. J Med Food. 2005;8(2):184-189.

Smith HS. Opioid metabolism, Mayo Clinic Proceedings. Elsevier. 2009. pp. 613-624.

Taherian AA, Babaei M, Vafaei AA, Jarrahi M, Jadidi M, Sadeghi H. Antinociceptive effects of hydroalcoholic extract of Thymus vulgaris. Pak J Pharm Sci. 2009;22(1):83-89.

Thompson JD, Tarayre M, Gauthier P, Litrico I, Linhart YB. Multiple genetic contributions to plant performance in Thymus vulgaris. J Ecol. 2004:92(1):45-56.

Tsuji R, Isobe N, Kurita Y, Hanai K, Yabusaki Y, Kawasaki H. Species difference in the inhibition of pentobarbital metabolism by empenthrin. Environ Toxicol Pharmacol. $1996 ; 2(4): 331-337$.

Vogel H. Drug discovery and evaluation: Pharmacological assays. Berlin: Springer; 2008. 
Vogt-Eisele A, Weber K, Sherkheli M, Vielhaber G, Panten J, Gisselmann G, Hatt H. Monoterpenoid agonists of TRPV3. Br J Pharmacol. 2007;151(4):530-540.

Wachtel-Galor S, Benzie I. Herbal medicine: an introduction to its history, usage, regulation, current trends, and research needs. In: Benzie IFF, Wachtel-Galor S, editors. Herbal Medicine: Biomolecular and Clinical Aspects. 2nd edition. Boca Raton (FL): CRC Press/Taylor \& Francis; 2011. Chapter 1.
Wagner H, Wierer $\mathrm{M}$, Bauer R. In vitro inhibition of prostaglandin biosynthesis by essential oils and phenolic compounds. Planta Med.1986;Jun(3):184-187.

Xu H, Delling M, Jun JC, Clapham DE. Oregano, thyme and clove-derived flavors and skin sensitizers activate specific TRP channels. Nat Neurosci. 2006;9(5):628-635.

Received for publication on 04 October 2018 Accepted for publication on $16^{\text {th }}$ January 2019 